\section{A SPHYGMOGRAPHIC EXPERIMENT}

$A \mathrm{~N}$ experiment which I have recently been enabled to A make by means of the sphygmograph may perhaps be of sufficient interest to deserve a brief record in your columns.

It occurred to me while preparing for the Croonian lectures, which I had the honour of delivering before the College of Physicians a few weeks back, that some light might be thrown on the movement of the blood in the vascular system, if an ordinary tracing of the healthy pulse were compared with one taken under different circumstances, wherein a large portion of the arteriocapillary network was thrown out of the circuit. By the kind assistance of my colleagues, Dr. Sharkey, Mr. Pitts, and Mr. Sandwith, I was able to put this hypothesis to the test, the result being the four pairs of tracings accompanying this communication. The patient in the first case (No. I) was Mr. Butler, a pupil of the.St. Thomas's Hospital, and in the last three instances one of the porters in this institution. The modus operandi was very simple. The sphygmograph having been firmly applied to the left

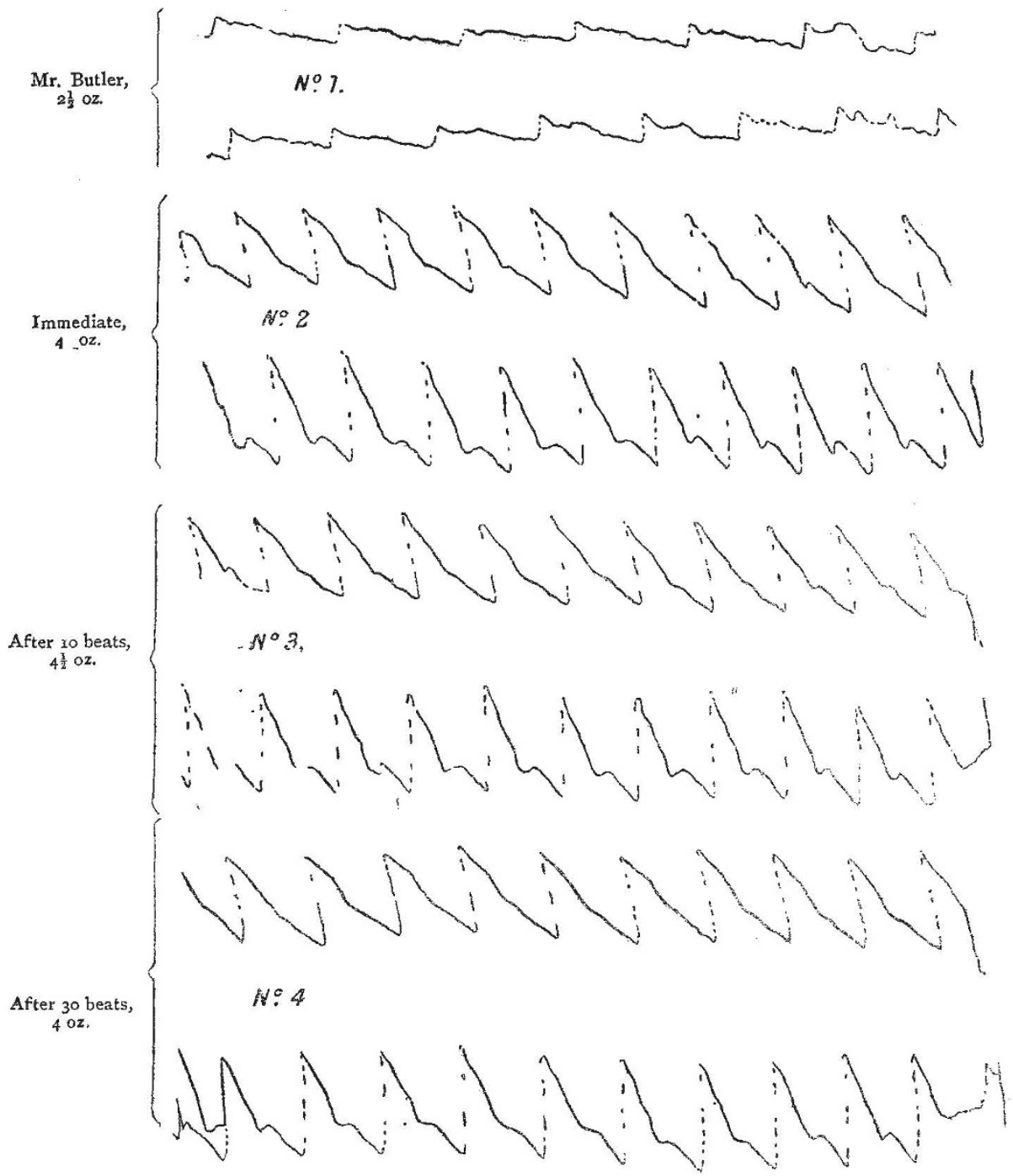

In all the tracings the lower is the normal pulse, the upper one with vessels compressed. Nos. 2, 3, 4, from the same patient, George Watts, æt 37 .

radial pulse, a series of tracings was made to ascertain the pressure which produced the most characteristic curve-line. This proved in Mr. Butler's case to be two and $a$ half, in that of the porter, four or four and a half ounces. This adjustment having been obtained, a normal tracing was taken on a broad slip of smoked plate glass at its lower portion. The three gentlemen abovenamed were instructed to compress simultaneously the two femoral arteries and the right axillary. A second tracing was then taken on the upper half of the same slip, so that it could be accurately compared with that already taken. Mr. Butler's pulse, even after it had been excited by the administration of a full dose of whisky (about three ounces), was too quiet and undemonstrative to give very striking results, though it will be seen that the excursion is diminished, the rate is rendered perceptibly slower in the ratio of six to seven, and the distinctive aortic notch is obscured by a number of smaller undulations. In the case of the porter we had to deal with an older man, of very muscular build, with a strong bounding, though not morbid pulse, who has been for some years in a Guards regiment. The first pair of tracings (No. 2) here showed a very important modification in the contour of the undulation. To eliminate any error due to a 
merely transitory change, ten full pulsations were in the second case (No. 3) allowed to elapse after the complete closure of the three large vessels above-named, before the second tracing was taken, and in the third trial (No. 4) thirty beats were steadily counted with the vessels occluded, before the second tracing was obtained. Beyond this I did not feel justified in going, for fear of phlebitic or thrombotic accidents. It will be seen, however, that the change of character in the wave becomes decidedly more marked in each succeeding instance than in that preceding it. IIt consists roughly in the total obliteration of the dicrotic wave termed the "aortic notch." Accompanying this is an increase of rapidity and suddenness in the line of ascent, which, from being nearly vertical in the uncompressed, bends distinctly backwards in the compressed tracings, thus reproducing the circular arc in which the index of the sphygmograph travels. The latter fact might have been anticipated, but the former is curious, and $I$ believe novel. The compressed tracings might be mistaken by an observer not acquainted with their mode of production, for those of a patient in whom the competency of the aortic valves was gravely impaired, and where the reflux of blood into the ventricle, which, in a healthy condition is prevented by their sudden closure, was freely taking place. On the plausible supposition that the dicrotic wave is a return undulation, a sort of echo sent back from the distal extremity of the arterial tree, it may be suggested that the great shortening thus artificially produced in the wave-length of the fluid undulation causes the primary and dicrotic waves to merge into one another.

I may say that neither of my patients felt any inconvenience from the experiment, either during compression or afterwards. An attempt was made to cut the internal iliacs also out of circuit by compressing the abdominal aorta before its bifurcation; but though to a good anatomist like Mr. Pitts the occlusion of this large vessel was not difficult, it caused so much hiccup and respiratory spasm as to render the continuity of the tracing uncertain.

W. H. STONE

\section{THE ELECTRIC LIGHT}

$W^{\mathrm{E}}$ have already referred to the Albert Hall Exhibition, and its important bearing on the progress of electric lighting by bringing together the various methods by which it has been proposed to utilise electricity for this purpose. Since then the newspapers have brought us intimations of further progress which it is stated Mr. Edison has made, and as our readers doubtless know, he has taken out one or more patents for various alleged improvements. We have borne, and will continue to bear, willing testimony to the marvellous ingenuity of Mr. Edison in his application of various scientific principles, resulting in inventions that a year or two ago were scarcely dreant of. We cannot but have the sincerest wish for Mr. Edison's success in whatever he puts his hand to; and his position as an inventor is so high that he needs not to take any trouble to make it more exalted by allowing exaggerated and misleading statements to go forth as to what he is about to do.

We have recently heard a great deal of Mr. Edison's experiments and promises with reference to the electric light. He startled the world in August last by announcing a great discovery which was to revolutionise the modes of artificial illumination at present in use, but we fear his discovery turned out to be something very like a ridiculus mus. Two of his patents have been published; one contains what we must deem a grave scientific error, the other the best authorities consider a mere reproduction of things that have been patented before by Staite, Harrison and others. Up to the present, so far as we can make out, he has done nothing new nor has he produced any- thing practical. The reports of newspaper interviewers are scarcely worthy of attention. Mr. Edison himself complains bitterly of their importunity and irrepressibility; but why, then, does he seem to stamp them with his approval by distributing their reports from his own laboratory? We cannot but think it a misfortune that he has kept at arms' length the electricians of New York, not one of whom, according to his own statement, has been allowed to enter his laboratory. We are therefore entirely dependent upon the New York press for our knowledge of his progress.

$\mathrm{He}$ has laid aside for the present his incandescent light and is experimenting with the Wallace form--his reason being that "everybody knows what the carbon lamp is, and besides it is not my lamp." $\mathrm{He}$ is engaged upon a new dynamo-machine-let us hope not his tuning-fork arrangement-but for what reasons he has put aside such perfect machines as the Siemens and the Gramme we are not enlightened. Dr. Hopkinson has recently shown that the Siemens' machine utilises 90 per cent. of the energy thrown into it. The Gramme is not far behind this. Mr. Edison can scarcely hope to improve on either. Again, the Brush and Wallace-Farmer machines are very efficient. Indeed, we scarcely want to improve the machine for producing currents. It is the lamp that needs the thought and work of the inventor, for no lamp yet exists worthy of the name.

The propagation by the daily press of scientific "discoveries" hot from the brain before they are allowed to be cooled down by the test of experiment is an invention upon which we cannot compliment our American friends. It does not conduce to the progress of science nor does it redound to the credit of the discoverer. We are accustomed on this side of the water to learn of new discoveries through the medium of well prepared and carefully digested papers submitted to one of our societies. There are such societies in America, but the records of such societies have to be searched in vain for any experiments or discoveries of Mr. Edison. We think it is matter for sincere regret that he prefers to promulgate what he conceives to be new through "our special correspondent," and the science dished up by these gentlemen is something wonderful to read. Thus says one paper :-

"Being questioned as to the subdivision of the electric light, the inventor said: 'The question is very simple. If you take a lamp in which the voltaic arc is produced from two carbon pencils, the more current you put on the faster the pencils are consumed and the resistance offered is lessened. There necessarily results a great waste of power. If the lamp is limited to 250-candle-light, it costs too much. By my plan the resistance is almost entirely at the lanip. The resistance of the conductor is to the resistance of the lamp as $\mathrm{I}$ to 100 . The resistance of my lamp is as 192 against $I$ to the resistance of the carbon lamp. You may consider the question most intelligently by taking a gas-burner as an example. If you have a half-inch gas-pipe and light the escaping gas without putting on a burner, how much gas-light can you get from an adjoining burner? Very little. But if you put in the half-inch pipe a burner, with a pin-hole in it, you get a light without interfering with other burners. The same condition obtains in electric lighting. The carbon lamp represents the half-inch gas-pipe; the pinhole burner represents my lamp.' 'But is not the electric current exhausted, not with regard to the resisting agent, but according to the square of the distance travelled?' 'No. If you are supplying a. mile of wire and then add another mile, the current will be weakened equally throughout the whole line, but not to that extent. If you keep on extending your line, you will have to make your conductor thick and add more power.' 'How do you propose to carry this theory into effect?' 'I shall have, proceeding from the central station, where a steamengine and a series of dynamo-machines are placed, a. 